J-ABDIPAMAS (Jurnal Pengabdian Kepada Masyarakat)

Vol. $2 \bullet$ No. $2 \bullet 2018$

ISSN : 2581-1320 (Print) ISSN : 2581-2572 (Online)

Homepage: http://ejurnal.ikippgribojonegoro.ac.id/index.php/J-ABDIPAMAS

\title{
KELOMPOK SADAR WISATA (POKDARWIS) DESA WISATA LIMBASARI KECAMATAN BOBOTSARI KABUPATEN PURBALINGGA
}

\author{
Zulia Karini ${ }^{1}$, Hendra Marcos $^{2}$, Yusida Munsa Idah $^{3}$ \\ ${ }^{1}$ STMIK AMIKOM Purwokerto. Email: zulia@amikompurwokerto.ac.id \\ 2STMIK AMIKOM Purwokerto. Email: hendra.marcos@amikompurwokerto.ac.id \\ 35TMIK AMIKOM Purwokerto. Email: myzidan 11@yahoo.co.id
}

\begin{abstract}
Tourism Awareness Group (POKDARWIS) Limbasari is group that manages various tour packages in Limbasari village, Bobotsari District, Purbalingga Regency. The tour activity packages that offered by Limbasari village are, River Tubing and Outbound, and homestay packages. Some local and foreign tourists come and stay and do rural tourism activities for one to two days before the main activities. The main problem of this group is communication problem with the foreign tourist. The other problem is, there is brochures of Homestay managers and tour packages for tourist causing the number of visitors decease from year to year. This is also due to the absence of a website that is developing optimally and up to date. The solution provided is by giving English language training, brochure-making training, training in creating and managing websites to partners. The method of carrying out activities includes discussions with partners, English language training and training in creating websites and brochures.
\end{abstract}

Keywords: POKDARWIS, tourist village, Limbasari

\begin{abstract}
ABSTRAK
Kelompok Sadar Wisata (POKDARWIS) Limbasari adalah kelompok yang mengelola berbagai paket wisata di Desa Limbasari, Kecamatan Bobotsari, Kabupaten Purbalingga. Jenis kegiatan yang ditawarkan di Desa Limbasari adalah River Tubing dan Outbound, dan paket homestay. Beberapa wisatawan lokal dan asing datang dan tinggal dan melakukan kegiatan wisata pedesaan selama satu hingga dua hari sebelum kegiatan utama. Hambatan utama yang dihadapi kelompok ini adalah masalah komunikasi dengan wisatawan assing. Hambatan lain yaitu belum adanya brosur yang lengkap untuk pengelola wisata dan paket homestay bagi wisatawan menyebabkan jumlah pengunjung menurun dari tahun ke tahun. Hal ini disebabkan tidak adanya situs web yang berkembang secara optimal dan up to date. Solusi yang disediakan adalah dengan memberikan pelatihan bahasa Inggris, pelatihan pembuatan brosur, pelatihan dalam membuat dan mengelola situs web untuk mitra. Metode pelaksanaan kegiatan termasuk diskusi dengan mitra, pelatihan bahasa Inggris dan pelatihan dalam membuat situs web dan brosur.
\end{abstract}

Kata Kunci: POKDARWIS, desa wisata, Limbasari

\section{PENDAHULUAN}

Desa wisata adalah kawasan pedesaan yang memiliki beberapa karakteristik khusus untuk menjadi daerah tujuan wisata (Inskeep, 2010). Menurut Nuryanti dalam Budasi (2012) kawasan desa wisata juga harus memiliki berbagai fasilitas untuk menunjangnya sebagai kawasan tujuan wisata. Berbagai fasilitas ini akan memudahkan para pengunjung desa wisata dalam melakukan kegiatan wisata. Fasilitas yang dimiliki oleh kawasan desa wisata antara lain sarana akomodasi yaitu menyediakan sarana penginapan berupa pondok-pondok wisata (homestay) sehingga 
para pengunjung dapat menikmati suasana pedesaan yang masih khas. Desa Wisata Limbasari adalah Desa Wisata yang ada di Kabupaten Purbalingga.

POKDARWIS PATRAWISA merupakan salah satu Kelompok Sadar Wisata yang mengelola berbagai paket wisata di Desa Wisata Limbasari Kecamatan Bobotsari Kabupaten Purbalingga. Berdasarkan hasil wawancara dengan Ketua POKDARWIS PATRAWISA, POKDARWIS ini dibentuk pada tanggal 5 Februari 2013 yang dibentuk oleh Dinas Kebudayaan Pariwisata Pemuda dan OlahRaga (DINBUDPARPORA) pada waktu itu yang sekarang menjadi Dinas Pemuda OlahRaga dan Pariwisata (DINPORAPAR) Kabupaten Purbalingga yang disahkan oleh Kepala Desa Limbasari pada saat itu. POKDARWIS ini beranggotakan 30 orang anggota aktif maupun pasif. Kelompok ini berasal dari gagasan oleh beberapa anggota dari Basecamp Utara yang merupakan komunitas penggiat wisata alam di Desa Limbasari.

POKDARWIS Desa Wisata Limbasari memiliki beberapa paket wisata untuk dipasarkan, yaitu River Tubing, Camping, Heel Treking, wisata kuliner pembuatan gula jawa dan juga Outbond. Berdasarkan hasil observasi, pada saat ini POKDARWIS PATRAWISA Desa Wisata Limbasari menerapkan teknik bisnis Consumer to Consumer(C2C) dalam mempromosikan objek wisata yang ada. C2C ( Customer to Customer ) merupakan model bisnis dimana konsumen bertindak sebagai penjual atau penyedia jasa yang menyediakan barang atau jasanya ke konsumen lainnya. Pada model bisnis C2C konsumen berhubungan langsung dengan konsumen lainnya tanpa melalui perantara (Putra, 2017).

Meskipun informasi mengenai Desa Wisata Limbasari sudah masuk dalam website, namun website tersebut belum dikembangkan secara optimal dan informasi yang tertera belum lengkap.

Jenis kegiatan yang paling banyak diminati oleh pengunjung di Desa Wisata Limbasari adalah River Tubing dan Outbond, namun jumlah pengunjung destinasi wisata tersebut cenderung menurun selama tiga tahun terakhir ini.

Berdasarkan wawancara dengan sekretaris komunitas Basecamp Utara, ditemukan bahwa berbagai kegiatan yang ditawarkan oleh kelompok sadar wisata kepada wisatawan yang datang sangat menarik wisatawan untuk datang dan menginap dan wisatawan yang datang tidak hanya dari lokal, bahkan beberapa wisatawan asing pun nampak datang mengunjungi Desa Wisata Limbasari ini. Dengan adanya wisatawan asing yang berkunjung, maka kendala bahasa dalam hal ini Bahasa Inggris menjadi masalah utama bagi anggota POKDARWIS, khususnya ketika mereka hendak menjelaskan perihal objek wisata ataupun paket wisata yang akan ditawarkan.

Berdasarkan observasi dan interview, dan juga hasil analisis situasi diatas ditemukan bahwa Mitra ini menghadapi beberapa permasalahan. Pertama, dengan adanya wisatawan yang tidak hanya wisatawan lokal namun wisatawan asing juga datang ke Desa Limbasari dan Desa Siwarak, menjadikan bahasa menjadi kendala utama berkomunikasi bagi anggota POKDARWIS Desa Limbasari. Bahasa Inggris tidak sepenuhnya dikuasai oleh beberapa anggota POKDARWIS, sehingga apabila ada wisatawan dari mancanegara berkunjung ke desa mereka kesulitan dan tidak dapat menjelaskan kegiatan-kegiatan maupun objek-objek wisata yang ada secara maksimal. 
Permasalahan kedua, pengelola homestay dan pengelola program paket wisata belum memiliki brosur yang komprehensif bagi wisatawan hal ini berkontribusi dalam penurunan jumlah pengunjung di Desa Wisata Limbasari.

Permasalahan ketiga yang dijumpai yakni mengenai pemasaran potensi wisata yang saat ini tampak baru sebatas informasi dari mulut ke mulut, sehingga kedatangan wisatawan ke daerah ini belum bersifat masif namun hanya bersifat "tujuan wisata persinggahan sejenak" (drop by destination). Kalaupun ada web namun belum berkembang secara optimal dan perlu di update.

Tujuan dari program pengabdian ini yakni:1) Memberikan pelatihan bahasa Inggris kepada kelompok mitra POKDARWIS. Pelatihan ini mencakup pelatihan bahasa Inggris dasar, 2) Memberikan pelatihan kepada kelompok mitra POKDARWIS tentang pembuatan media promosi non-digital berbasis komputer dengan menggunakan software pengolah grafis. Selain itu juga akan diberikan pelatihan pembuatan media promosi digital melalui media sosial seperti instagram dan facebook, 3) Pelatihan pembuatan, pengelolaan dan optimalisasi website yang lebih komprehensif dan up to date kepada kelompok mitra POKDARWIS. Dalam website ini berisi: Peta Lokasi, gambaran umum desa wisata, paket wisata beserta daftar harga paket wisata yang ditawarkan, daftar homestay yang tersedia.

\section{METODE PELAKSANAAN}

Metode yang digunakan untuk memecahkan masalah yang ada di POKDARWIS Desa Wisata Limbasari adalah a) Diskusi tentang keunggulan penerapan teknologi seperti website dan brosur serta kontribusinya dalam penanggulangan dalam manajemen desa wisata, Pelatihan secara langsung bahasa Inggris, pembuatan web dan pembuatan brosur serta kontribusinya dalam penanggulangan dalam manajemen desa wisata, c) Praktek langsung penggunaan produk yang telah dihasilkan.

Kegiatan diskusi, pelatihan serta praktik yang dilakukan dalam kegiatan ini diharapkan mampu meningkatkan pemahaman serta keterampilan bagi anggota POKDARWIS Desa Wisata Limbasari.

Menyadari adanya permasalahan yang muncul maka tim pengusul telah melakukan beberapa hal untuk membantu Kelompok Sadar Wisata (POKDARWIS) Desa Wisata Limbasari dalam mengatasi permasalahan antara lain sebagai berikut: (1) Memberikan pelatihan bahasa Inggris kepada kelompok mitra POKDARWIS. Pelatihan ini mencakup pelatihan bahasa Inggris dasar. Hal ini penting dilakukan agar para anggota dapat berkomunikasi seputar objek wisata dan kegiatan sehari-hari yang terjadi di desa mereka dengan orang asing. Pelatihan Bahasa Inggris ini akan diselenggarakan di desa Limbasari dengan menyediakan tenaga pengajar yang kompeten dan juga ikut melibatkan mahasiswa aktif STMIK AMIKOM Purwokerto sejumlah 2 orang. (2) Memberikan pelatihan kepada kelompok mitra POKDARWIS tentang pembuatan media promosi non-digital berbasis komputer dengan menggunakan software pengolah grafis berupa brosur yang berisi: Peta Lokasi objek dan atraksi wisata, brosur homestay beserta daftar harga kamar (published room rates) dan brosur paket wisata. Selain itu juga akan diberikan pelatihan pembuatan media 
promosi digital melalui media sosial seperti instagram dan facebook.Pelatihan pembuatan brosur digital dan brosur non-digital akan diselenggarakan di desa Limbasari dengan menyediakan tenaga pengajar yang kompeten dan juga ikut melibatkan mahasiswa aktif STMIK AMIKOM Purwokerto sejumlah 2 orang. (3) Pelatihan pembuatan, pengelolaan dan optimalisasi website yang lebih komprehensif dan up to date kepada kelompok mitra POKDARWIS. Dalam website ini berisi: Peta Lokasi, gambaran umum desa wisata, paket wisata beserta daftar harga paket wisata yang ditawarkan, daftar homestay yang tersedia. Pelatihan pembuatan dan pengelolaan website ini akan diselenggarakan di desa Limbasari dengan menyediakan tenaga pengajar yang kompeten dan juga ikut melibatkan mahasiswa aktif STMIK AMIKOM Purwokerto sejumlah 2 orang

Partisipasi mitra dalam hal ini pelaksanaan program pengabdian sangat menentukan keberhasilan dan keberlanjutan program. Untuk melancarkan kegiatan pelatihan keterampilan Bahasa Inggris dan pelatihan pembuatan website dan brosur dan untuk mendorong mitra agar memberikan partisipasi aktif dalam pelaksanaan program pengabdian, untuk itu pelaksanaan program ini akan dibantu mahasiswa aktif STMIK AMIKOM Purwokerto sebagai trainer sasaran program pengabdian, hal ini guna menunjukkan peran penting mahasiswa.

\section{HASIL DAN PEMBAHASAN}

Program pengabdian kepada masyarakat ini telah dilaksanakan di Desa Limbasari Kabupaten Purbalingga pada hari/tanggal Kamis, 9 Agustus 2018. Peserta kegiatan adalah para pemuda yang tergabung dalam kelompok sadar wisata desa Limbasari. Pengabdian masyarakat ini mengacu pada program pengabdian yang telah dilaksanakan oleh I Gede Budasi pada tahun. 2012 dengan mengangkat judul: IbM Kelompok Sadar Wisata. Dalam program pengabdiannya, Budasi dkk (2012) mengangkat Desa Wisata Menyali, Bali sebagai mitranya. Permasalahan yang dihadapi yakni belum pahamnya anggota sadar wisata Desa Menyali secara mendalam tentang objek dan atraksi Desa Menyali serta deskripsinya secara mendetail, seperti: lokasinya, sejarahnya, kepercayaan masyarakatnya, ritual serta makna yang terkandung di dalamnya. Pada umumnya mereka belum memiliki kemampuan yang memadai yang bisa memberikan penjelasan tentang objek dan atraksi wisata yang ada di Desa Wisata Menyali, pengelola akomodasi dan program trekking belum memiliki brosur yang komprehensif bagi wisatawan dan belum memiliki situs website yang dapat dibaca secara online oleh calon wisata yang tertarik akan wisata pedesaan.

Mengacu pada pengabdian yang telah dilaksanakan oleh Budasi dkk (2012) tersebut maka penulis menemukan permasalahan yang serupa di Desa Wisata Limbasari, dimana anggota sadar wisata Desa Wisata Limbasari belum memiliki kemampuan yang memadai dalam menjelaskan objek dan atraksi wisata dalam bahasa Inggris juga belum terdapat brosur dan situs website yang komprehensif agar dapat menarik wisatawan lokal dan asing datang berkunjung. Dalam program pengabdian yang dilaksanakan oleh Budasi dkk (2012) hanya memberikan pelatihan tentang caracara menjelaskan objek dan atraksi wisata yang ada Desa Menyali. Juga diberikan 
dalam pelatihan adalah pembuatan presentasi produk wisata Desa Menyali dalam wujud Slide Show untuk dipresentasikan. Sedangkan dalam program pengabdian yang dilakukan penulis di Desa Wisata Limbasari adalah lebih menekankan pada pelatihan bahasa Inggris yakni percakapan sehari-hari yang sederhana yang dapat dipraktekkan apabila ada wisatawan asing.

Sehubungan dengan hal tersebut, maka materi pertama yang diberikan kepada mitra adalah melatih Bahasa Inggris agar mereka mampu berkomunikasi secara aktif kepada turis asing yang datang berkunjung. Bentuk kegiatannya adalah pemberian kosakata seputar objek wisata dan kosakata kegiatan sehari-hari dan beberapa ungkapan umum tentang topik-topik seputar kehidupan sehari-hari kemudian mitra praktek langsung berkomunikasi dengan Bahasa Inggris. Peserta diberikan materi dasar tentang percakapan sehari-hari dengan topic sebagai berikut:

\section{Introduction}

Melatih peserta bagaimana cara memberi salam dalam Bahasa Inggris, bagaimana cara memperkenalkan diri sendiri kepada orang asing yang berkunjung ke tempat mereka. Berikut materi tentang perkenalan yang diberikan:

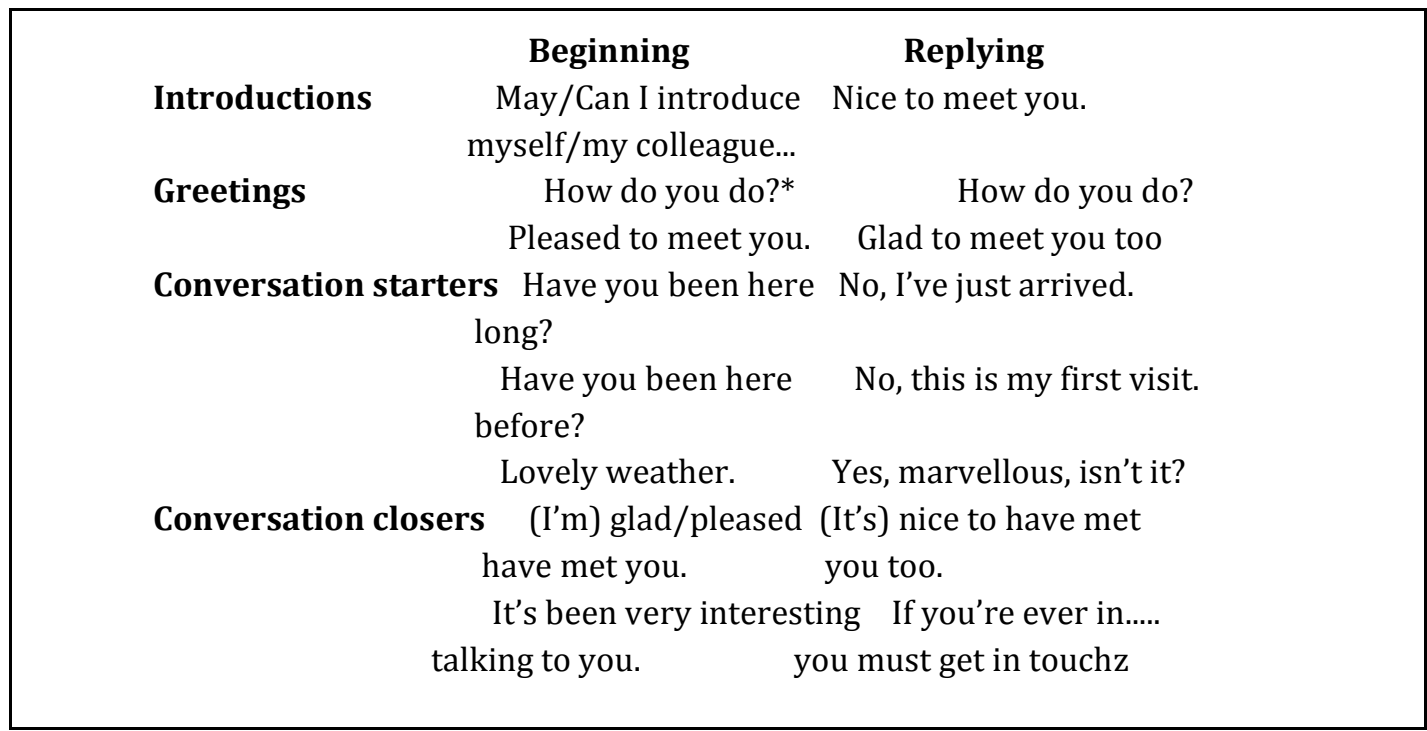

\section{Asking and giving direction}

Memberikan materi tentang bagaimana memberikan arah/petunjuk kepada orang asing yang sedang bertanya tentang suatu lokasi. Peserta langsung mempraktekkan percakapan sederhana dengan sesame peserta lainnya.

Berikut ini materi tentang asking dan giving direction yang diberikan:

Starting to conversation kindly is very good way. So, when we start talking, we can use the following forms:

Examples:

- Excuse me / Excuse me sir or madam.

. I am new here.

- I'm lost.

- I am sorry to interrupt you, but...

- Excuse me, could you help me, please?

- I am sorry. 
- Sorry, I am not from around here.

- Excuse me madam, I seemed to be lost.

- Hello / Hello sir or madam.

Asking direction:

Examples:

- Can you give me directions to the nearest hospital?

- Are we on the right road for London?

- How do you get to the bus stop?

. Where is the carnival?

- Where can I find the nearest car park?

- How do I get to library?

- Is there a pet shop near here?

- Where is the nearest post office?

- Do you know where the shopping center is?

- Is there a sports shop around here?

- Can you tell me how to get to train station from here?

Vocabulary of Giving Direction

- It is on the left

- It is on the right

- It is straight on

- opposite

- near

- next to

- between

- at the end of Oxford street

. on the corner of James road

- at the end of Stanley Street

- Behind the Petrol station

. in front of the Mall

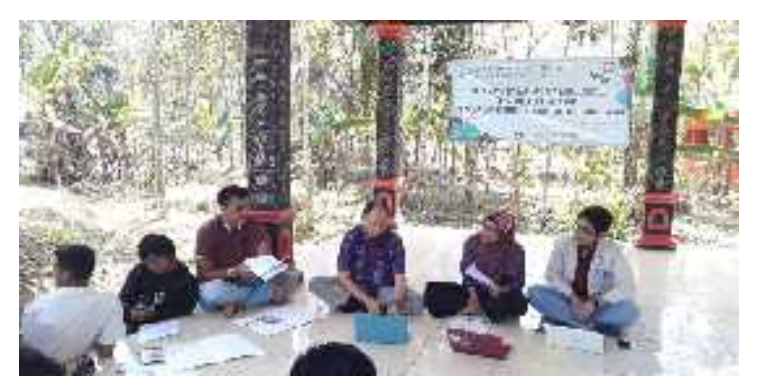

Gambar 1 pemberian materi dasar bahasa Inggris

Materi kedua yang diberikan sesuai dengan permasalahan yang dihadapi oleh mitra yakni tidak adanya brosur yang komprehensif mengenai kegiatan wisata di desa Limbasari. Selama ini untuk menarik pengunjung hanya dilakukan dari mulut ke mulut. Oleh karena itu, diberikan pelatihan merancang dan membuat brosur bagi anggota kelompok sadar wisata Desa Limbasari. Pelatihan perancangan brosur ini dengan 
menggunakan aplikasi Corell Draw 17. Disini, mitra diperkenalkan terlebih dahulu apa itu Corell Draw 17, cara memulai aplikasi, dan cara menggunakan aplikasi tersebut. Setelah itu masing-masing anggota mulai merancang brosur desa Wisata Limbasari. Di dalam rancangan brochure tersebut terdapat menu antara lain: kegiatan wisata yang ditawarkan oleh Desa Wisata Limbasari dan homestay yang dapat dijumpai di desa Wisata Limbasari. Rancangan brosur ini dilengkapi dengan gambar-gambar terkait kegiatan wisata yang ditawarkan.

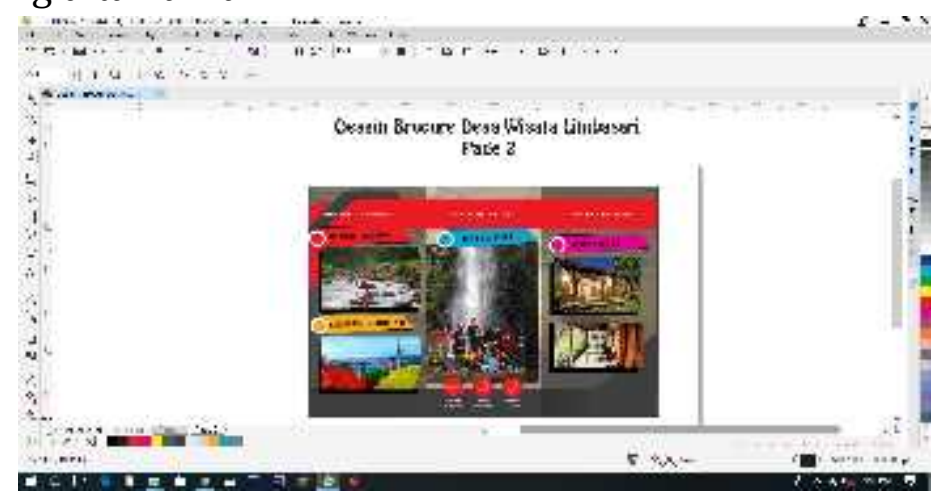

Gambar 2 Rancangan Brosur untuk Desa Wisata Limbasari

Materi ketiga yang diberikan untuk anggota sadar wisata Desa Wisata Limbasari yakni pelatihan tentang pengenalan dan pembuatan website. Hal ini merujuk pada permasalahan yang ada bahwa di Desa Wisata Limbasari belum terdapat Website yang up to date. Selain itu, beberapa dari mitra belum memahami apa itu website, bagaimana cara membuat dan mengelolanya. Pada kesempatan ini, mitra diajarkan cara membuat website dengan menggunakan aplikasi yang sudah ada. Membuat website menggunakan aplikasi yang sudah ada disebut membuat website menggunakan platform atau orang-orang IT sering menyebutnya CMS atau Content System Management. Sesuai dengan namanya CMS bisa merubah konten website tanpa harus memahami bahasa program, untuk menambah, merubah dan bahkan menghapus halaman website itu seperti menggunakan microsoft word. Pada pelatihan website ini mitra berlatih membuat dan merancang website dengan menggunakan platform wordpress. Alasan menggunakan aplikasi ini karena aplikasi ini tidak dipungut biaya untuk mengunduh, install, atau modifikasi. WordPress didukung komunitas yang sangat besar dan sangat cocok untuk pemula. Pada saat pelatihan mitra berlatih membuat artikel tentang Desa Wisata Limbasari seperti: sejarah, wisatawisata yang ditawarkan, dan homestay yang tersedia di Desa Wisata Limbasari. Mitra juga berlatih membuat album foto, formulir kontak, dengan sangat mudah di rancangan website ini. Berikut ini hasil rancangan website yang telah dibuat untuk Desa Wisata Limbasari. Di dalam rancangan website ini terdapat beberapa menu yaitu: menu beranda, menu sejarah, menu wisata, menu homestay, menu hubungi kami. Di dalam tiap-tiap menu diberikan beberapa gambar yang mendukung dan menarik wisatawan. Juga terdapat beberapa info penting terkait Desa Wisata Limbasari. 


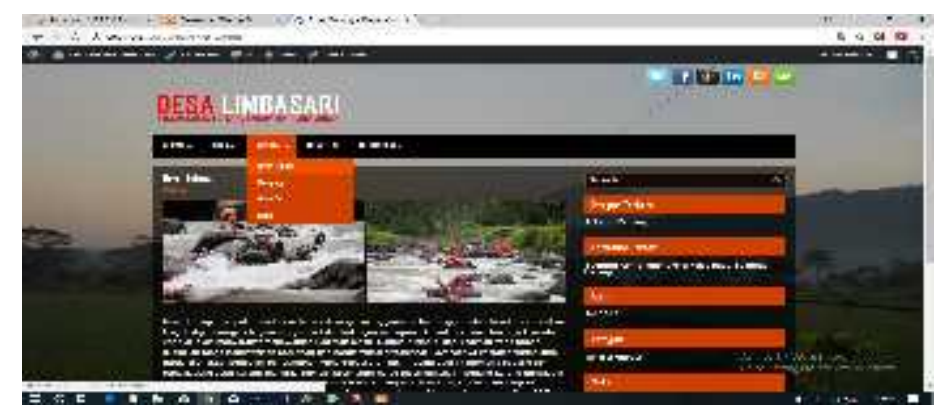

Gambar 3 Rancangan Website untuk Desa Wisata Limbasari

Program pengabdian kepada masyarakat di Desa Wisata Limbasari telah berhasil dilaksanakan tanpa adanya kendala apapun. Mitra mendapatkan banyak pengetahuan terkait dengan penggunaan bahasa Inggris dalam kehidupan sehari-hari, perancangan brosur dan website. Penulis mengharap kedepan sangat diperlukan adanya upaya yang lebih besar lagi dari segenap masyarakat Desa Limbasari dan pemerintah mengupayakan cara yang efektif dalam memasarkan potensi wisata desa ini kepada masyarakat dunia (wisatawan lokal maupun internasional). Program pengabdian kepada masyarakat (PKM) tidak hanya diarahkan pada kepada kelompok sadar Wisata Desa Limbasari, namun juga diarahkan pada kelompok masyarakat yang lain dan sekitarnya terutama masyarakat desa yang terkait dan mendukung kegiatan pariwisata pedesaan yang lain yang belum tersentuh dalam kegiatan PKM ini.

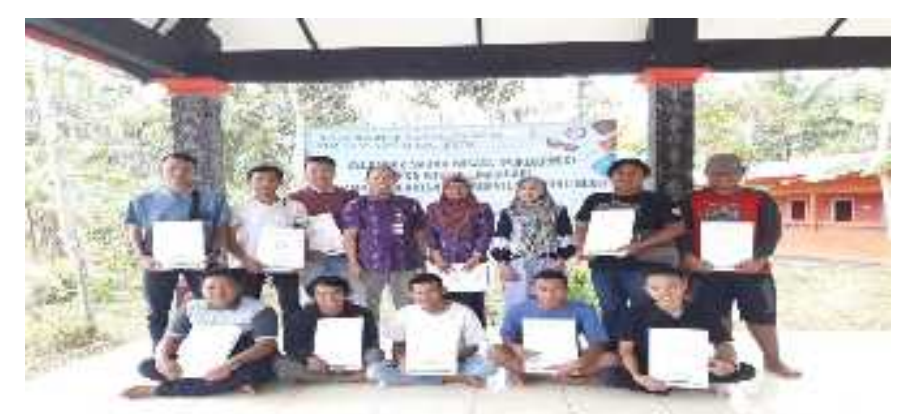

Gambar 4 Selesai kegiatan bersama mitra dan instruktur pelatihan

\section{SIMPULAN}

Setelah mengikuti pelatihan peserta mendapatkan beberapa keahlian. Pertama, peserta dapat berkomunikasi sederhana dengan menggunakan bahasa Inggris, antara lain dapat memberi salam, menyapa, menanyakan keadaan, memberikan petunjuk/arah, menawari bantuan, menjelaskan/mendeskripsikan tempat/lokasi wisata. Kedua, peserta dapat membuat media promosi berupa: peta lokasi objek atraksi wisata, brosur homestay. Ketiga, peserta bisa membuat website tentang potensi Wisata Desa Limbasari.

\section{UCAPAN TERIMA KASIH}

Kami mengucapkan terima kasih kepada LPPM STMIK AMIKOM Purwokerto yang telah mendanai kegiatan pengabdian kepada masyarakat yang telah dilaksanakan 
tanpa ada kendala apapun dan terima kasih kepada mitra yang telah ikut serta berperan aktif dalam kegiatan ini.

\section{DAFTAR RUJUKAN}

Budasi, I Gede. (2012). IbM Kelompok Sadar Wisata. Laporan Akhir. Fakultas Bahasa dan Seni: Universitas Pendidikan Ganesha Singaraja. Diakses di https://anzdoc.com/laporan-akhir-program-ipteks-bagi-masyarakat-ibmkelompok-sa.html

Inskeep E. (2010). Tourism Planning An Integrated and Sustainable Development Approach. Oxford: OUP

Putra, R. S. (2017). Aplikasi M-Commerce Paket Wisata POKDARWIS PATRAWISA Di Desa Limbasari Berbasis Android. Skripsi. STMIK AMIKOM Purwokerto. 
82 J-Abdipamas, Vol. 2, No. 2, Oktober, 2018 